\title{
Presença de Campylobacter spp. em cortes refrigerados de frango
}

\section{Presence of Campylobacter spp. in refrigerated chicken cuts}

\author{
Juliane Alves $^{1 *}$; Tereza Cristina Rocha Moreira de Oliveira ${ }^{2}$
}

\begin{abstract}
Resumo
Campylobacter spp. é causa frequente de doença bacteriana transmitida por alimentos. As aves, especialmente o frango, são reservatórios de $C$. jejuni. O objetivo desse trabalho foi avaliar a presença de Campylobacter spp. em cortes refrigerados de frango comercializados em Londrina, Paraná. Um total de 50 amostras de cortes de frango, tais como, peito, coxa e sobrecoxa, foram analisadas. A confirmação da presença de Campylobacter spp. foi realizada por meio da reação em cadeia da polimerase das colônias características desenvolvidas em meio seletivo-diferencial. Das 50 amostras de carne de frango analisadas, 28 (56\%) foram positivas para Campylobacter spp. A carne de frango é um possível veículo de transmissão de Campylobacter para o ser humano. Este estudo ressalta a importância da avaliação da ocorrência de Campylobacter em carne de frango, devido ao número significativo de amostras positivas encontradas e a ausência de dados epidemiológicos acessíveis no Brasil. Além disso, podemos destacar a necessidade da orientação correta da população em relação à manipulação e cozimento da carne de frango para prevenir a infecção humana por Campylobacter spp.

Palavras-chave: Detecção, carne de frango crua, Campylobacter spp, segurança de alimentos
\end{abstract}

\begin{abstract}
Campylobacter spp. is a common cause of bacterial food-borne illness. Birds, especially poultry are primary reservoirs of $C$. jejuni. The aim of this study was to evaluate the occurrence of Campylobacter spp. in chicken cuts purchased in supermarkets of Londrina, Parana. A total of 50 samples of chicken cuts, such as breasts, thighs and drumsticks were analyzed. The confirmation of the presence of Campylobacter spp. was performed by identifying the suspected colonies on the selective medium using the polymerase chain reaction. Of the 50 samples analyzed, 28 (56\%) were positive for Campylobacter spp. Chicken meat, as observed in this study, is a possible source of Campylobacter transmission to humans. This study alerts for the importance to analyze the occurrence of Campylobacter in chicken meat, due to the significant number of positive samples observed and no available epidemiological data in Brazil. The correct orientation about handling and cooking of chicken meat is also necessary to prevent human infection by Campylobacter spp.

Key words: Detection, raw chicken meat, Campylobacter spp, food safety
\end{abstract}

\footnotetext{
${ }^{1}$ Discente de Doutorado do Programa de Pós-Graduação em Ciência de Alimentos, Dept ${ }^{\circ}$ de Ciência e Tecnologia de Alimentos, Centro de Ciências Agrárias, Universidade Estadual de Londrina, UEL, Londrina, PR. E-mail: julianealves@yahoo.com.br

${ }^{2}$ Prof $^{\mathrm{a}} \mathrm{Dr}^{\mathrm{a}}$ do Dept ${ }^{\mathrm{o}}$ de Ciência e Tecnologia de Alimentos, UEL, Londrina, PR. E-mail: terezaoliveira@yahoo.com

* Autor para correspondência
} 


\section{Introdução}

O Brasil é o terceiro produtor mundial de carne de frango e o primeiro exportador desse produto. $\mathrm{O}$ Estado do Paraná é o maior produtor brasileiro de carne de frango, seguido de Santa Catarina e Rio Grande do Sul. Em 2012 o Brasil produziu 12.645 mil ton toneladas de carne de frango e 30,98\% deste total foi destinado a exportação. $\mathrm{O}$ consumo per capita brasileiro ( $\mathrm{kg} / \mathrm{hab}$ ), passou de 29,91, em 2000, para 45, em 2012 (UBA, 2013).

\section{O gênero Campylobacter é constituído} por 18 espécies microaerófilas e as espécies patogênicas ao homem multiplicam-se em uma faixa de temperatura máxima de $46{ }^{\circ} \mathrm{C}$ e mínima de $30{ }^{\circ} \mathrm{C}$, sendo classificadas como termofílicas (HUMPHREY; O'BRIEN, S.; MADSEN, 2007). C. jejuni e C. coli são responsáveis por $95 \%$ dos casos de campilobacteriose em humanos e apenas 500 células são suficientes para causar infecção (MAZIERO; OLIVEIRA, 2010). Essas bactérias são comensais do trato gastrointestinal de uma série de animais domésticos e silvestres (bois, porcos, gatos, cães, roedores e aves) e as aves, especialmente o frango, são consideradas reservatórios primários de C. jejuni (FORSYTHE, 2002; PARK, 2002). $\mathrm{Na}$ maioria das vezes, o frango infectado por Campylobacter spp. não apresenta sintomas clínicos de doença, e isto representa um problema higiênicosanitário importante na linha de produção, podendo ser encontrado até $10^{9}$ UFC de Campylobacter por grama de fezes no trato intestinal destas aves (PARK, 2002).

A contaminação ambiental é apontada como a rota mais comum de transmissão de Campylobacter spp. para as aves (MEAD, 2004). A colonização das aves por esse patógeno pode ocorrer, principalmente, por transmissão horizontal, tais como, água, ração e cama contaminadas, animais domésticos e silvestres presentes na granja, trânsito de trabalhadores nos galpões, limpeza e desinfecção inadequada dos galpões e caixas de transporte de aves para o abate contaminadas (NEWELL; FEARNLEY, 2003).
A possibilidade de transmissão vertical não pode ser excluída, embora seja controversa e alvo de discussões (COX et al., 2012). A contaminação da carne pode ocorrer durante o abate e a bactéria aderida à pele forma um biofilme, que dificulta a sua remoção (ALTER et al., 2005).

Segundo o CDC (Centers for Disease Control and Prevention), a maioria dos casos de campilobacteriose ocorre esporadicamente e não como parte de surtos. Os sintomas mais comuns incluem náusea, cólicas abdominais e diarréia sanguinolenta. Nos Estados Unidos, apesar do número estimado anual de casos ser de aproximadamente 2,4 milhões, a maioria dos casos é autolimitada, com uma média de 124 óbitos por ano (CDC, 2009). Complicações pós infecção podem ocorrer, tais como, artrite, síndrome de Reiter e Síndrome de Guillain-Barré, uma doença auto-imune que ataca o sistema nervoso periférico, sendo esta considerada uma sequela da infecção causada especificamente por C. jejuni (LINTON; OWEN; STANLEY, 1996; BLASER, 1997; YAN et al., 2005; SIMMONS et al., 2008). A estimativa é que Campylobacter seja responsável por $5 \%$ a $14 \%$ dos casos de diarréia em humanos no mundo, e que, um a cada 1000 casos evoluam para Síndrome de Guillain Barré (HUMPHREY; O'BRIEN; MADSEN, 2007; OLSEN et al., 2009).

A Legislação Brasileira em vigor não estabelece padrões microbiológicos para Campylobacter em alimentos (BRASIL, 2001). Os casos de campilobacteriose são subdiagnosticados e subnotificados e não há fácil acesso a dados epidemiológicos.

Dado o exposto, o objetivo deste trabalho foi detectar a presença de Campylobacter spp. em cortes refrigerados de frangos comercializados na região de Londrina, PR.

\section{Material e Métodos}

Cinquenta amostras de cortes refrigerados de frango cru (peito, coxa e sobrecoxa), provenientes 
de frigoríficos com Serviço de Inspeção Federal (SIF), foram adquiridas em dois supermercados de Londrina, PR em suas embalagens originais. Amostras de três marcas diferentes foram coletadas aleatoriamente, mas nenhum lote foi repetido. Todas as amostras encontravam-se dentro do período de validade e armazenadas sob refrigeração, em temperaturas entre $2{ }^{\circ} \mathrm{C}-6{ }^{\circ} \mathrm{C}$. As amostras foram transportadas ao laboratório em caixas isotérmicas e conservadas em câmara fria à temperatura de $4^{\circ} \mathrm{C}$ até o momento da análise, que não excedeu $24 \mathrm{~h}$ após a compra.

Alíquotas de $25 \mathrm{~g}$ de pele de cada amostra de corte de frango foram transferidas assepticamente para sacolas de polipropileno estéreis adicionadas de $225 \mathrm{~mL}$ de água peptonada tamponada e massageadas manualmente por $30 \mathrm{~s}$. Um volume de $5 \mathrm{~mL}$ da água de enxaguadura da pele de frango foi enriquecido em $45 \mathrm{~mL}$ de caldo Bolton suplementado com Modified Bolton Broth Selective Supplement SR0208E (Oxoid) (cefoperazone, $10 \mathrm{mg} / 500 \mathrm{~mL}$; vancomicina, $10 \mathrm{mg} / 500 \mathrm{~mL}$; trimetropim, $10 \mathrm{mg} / 500 \mathrm{~mL}$ e anfotericina B, $5 \mathrm{mg} / 500 \mathrm{~mL}$ ) incubados à $42{ }^{\circ} \mathrm{C}$ por $24 \mathrm{~h} \mathrm{em}$ condições de microaerofilia $\left(5 \% \mathrm{O}_{2}, 10 \% \mathrm{CO}_{2}\right.$ e $85 \% \mathrm{~N}_{2}$ ).

Após o enriquecimento seletivo descrito anteriormente, alíquotas de $0,1 \mathrm{~mL}$ dos enxágues foram inoculadas em ágar Bolton suplementado com Modified Bolton Broth Selective Supplement SR0208E (cefoperazone, $10 \mathrm{mg} / 500 \mathrm{~mL}$; vancomicina, $10 \mathrm{mg} / 500 \mathrm{~mL}$; trimetropim, 10 $\mathrm{mg} / 500 \mathrm{~mL}$ e anfotericina B, $5 \mathrm{mg} / 500 \mathrm{~mL}$ ). As placas foram incubadas durante $48 \mathrm{~h}$ a $42{ }^{\circ} \mathrm{C}$, sob condições de microaerofilia $\left(5 \% \mathrm{O}_{2}, 10 \% \mathrm{CO}_{2}\right.$ e $85 \% \mathrm{~N}_{2}$ ). Colônias pequenas, redondas, lisas e translúcidas, características de Campylobacter spp., foram identificadas pela técnica de PCR.

Colônias características de Campylobacter foram transferidas da placa para microtubos contento $1 \mathrm{~mL}$ de água peptonada tamponada estéril. Essa suspensão foi centrifugada por $10 \mathrm{~min}$ a $16000 \times g$ e ressuspenso em $300 \mu \mathrm{L}$ de solução de lise TZ (ABOLMAATY et al., 2000) com a seguinte constituição: $2 \%$ de Triton X-100, 2,5 mg/ $\mathrm{mL}$ de azida sódica em Tampão Tris-HCl 0,1 M pH 8,0. Para a extração do DNA, as suspensões foram fervidas a $100{ }^{\circ} \mathrm{C}$ por $10 \mathrm{~min}$, resfriadas em banho de gelo por $5 \mathrm{~min}$ e centrifugadas por $5 \mathrm{~min}$ a 16000 $\times g$. Os sobrenadantes foram armazenados a $-20{ }^{\circ} \mathrm{C}$ e usados como DNA alvo para a PCR.

O par de iniciadores, específico para o gênero Campyobacter, empregado foi OT1559 (5'-CTGCTTAACACAAGTTGAGTAGG-3') (UYTTENDAELE etal., 1994; LÜBECK etal.,2003) e 18-1 (5'-TTCCTTAGGTACCGTCAGAA-3') (VANCAMP et al., 1993; DOCHERTY et al., 1996; LÜBECK, et al. 2003). Esses iniciadores amplificam uma sequência de $287 \mathrm{pb}$ do gene rRNA 16S.

As reações de amplificação foram realizadas com 4,0 $\mu \mathrm{L}$ de DNA, adicionados à uma mistura $(16 \mu \mathrm{l})$ constituída por tampão para PCR $1 \mathrm{X}(20 \mathrm{mM}$ Tris$\mathrm{HCl}, \mathrm{pH} 8,4,50 \mathrm{mM} \mathrm{KCl},, 5 \mathrm{mM}$ de $\mathrm{MgCl}_{2}, 0,2 \mathrm{mM}$ de dNTPs, 0,25 $\mu \mathrm{M}$ do par de iniciadores OT1559 e 18-1, 1,0 U de Taq DNA Polimerase. A reação de amplificação foi realizada em termociclador e as condições de amplificação foram desnaturação inicial a $95{ }^{\circ} \mathrm{C}$ por 10 mim, seguida de 40 ciclos de desnaturação a $95{ }^{\circ} \mathrm{C}$ por $10 \mathrm{~s}$, hibridação a $60{ }^{\circ} \mathrm{C}$ por $30 \mathrm{~s}$, polimerização da sequência alvo a $72{ }^{\circ} \mathrm{C}$ por $45 \mathrm{~s}$ e polimerização da sequência alvo final de 5 mim a $72{ }^{\circ} \mathrm{C}$. A cepa padrão Campylobacter jejuni ATCC 33291 foi utilizada como controle positivo em cada reação de amplificação e a extração de DNA realizada como descrito anteriormente. Água destilada ultra pura foi utilizada como controle negativo.

Após a PCR, em cada microtubo de $200 \mu \mathrm{L}$ contendo os produtos de amplificação foram adicionados $4 \mu \mathrm{L}$ de tampão de amostra Ficoll 400 15\%; azul de bromofenol 0,25\%. Alíquotas de $10 \mu \mathrm{L}$ dessa mistura foram analisadas em gel de agarose a $1,5 \%$ acrescidos de $0,02 \mu \mathrm{L} / \mathrm{mL}$ de SYBR ${ }^{\circledR}$ Safe 10,000x em DMSO (Invitrogen). A 
eletroforese foi realizada em cuba horizontal com tampão Tris borato EDTA [Tris $45 \mathrm{mM}$; ácido bórico $45 \mathrm{mM}$, EDTA $1,25 \mathrm{mM}$ ] a $70 \mathrm{~V}$ durante 1 h. Como marcador de massa molecular foi utilizado DNA de 100 pb. Os produtos de amplificação foram visualizados por luz UV em transiluminador.

\section{Resultados e Discussão}

Das 50 amostras de carne de frango analisadas, 28 (56\%) estavam contaminadas com Campylobacter spp. Todas as amostras que apresentaram colônias características no ágar Bolton foram identificadas como Campylobacter spp. pela PCR. A identificação fenotípica dessa bactéria é limitada devido à existência de isolados bioquimicamente atípicos, além de possuir um crescimento fastidioso e assacarolítico, o qual restringe o uso de testes bioquímicos diferenciais. A PCR possibilitou a identificação de Campylobacter diretamente de colônias isoladas na cultura e, como observado por outros autores, é uma excelente alternativa em relação à identificação bioquímica (HOORFAR; AHRENS; RÅDSTRÖM, 2000; JOFRÉ et al., 2005).

O controle da contaminação de carcaças de frango por Campylobacter spp. é uma exigência cada vez maior do mercado internacional, porque a carne de frango e derivados são os principais veículos de transmissão dessa bactéria patogênica para o ser humano (WHO, 2009).

Nos Estados Unidos, a média da percentagem de positividade de Campylobacter spp. em amostras de peito de frango variou de 30,7 a $71,5 \%$ entre os 11 estados monitorados, no período de 2002 a 2010, pelo National Antimicrobial Resistance Monitoring System (NARMS, Retail Meat Report, 2010). Segundo pesquisa realizada em 2008 pela European Food Safety Authority (EFSA), cerca de $80 \%$ das carcaças de frango comercializadas no mercado europeu estavam contaminadas com este patógeno e a prevalência de contaminação entre os Estados membros da União Européia variou de 5\% a 100\%
(EFSA, 2008).

Estudos realizados em diferentes regiões do Brasil mostraram percentagens de contaminação de carcaças de frango por Campylobacter que variaram de 14,2 a 93,3\% (DIAS et al., 1990; AQUINO et al., 2002; FRANCHIN; OGLIARI; BATISTA, 2007; LOPEZ, 2009; AZEREDO; LUCHESE; LAURIAFILGUEIRAS, 2010; CASARIL, 2010; COSTA, 2010; MAZIERO; OLIVEIRA, 2010). Estudos anteriores realizados com amostras coletadas na região de Londrina, Paraná mostraram percentagens de contaminação de 46,4\% (CASARIL, 2010) e 53,3 \% (MAZIERO; OLIVEIRA, 2010), inferiores as obtidas no presente trabalho.

A maioria dos estudos de avaliação da contaminação de carne de frango por Campylobacter são realizados com produtos refrigerados ou congelados disponíveis para compra em açougues e supermercados. O efeito do resfriamento e do congelamento de carne de frango na sobrevivência desta bactéria ainda não foi elucidado. Maziero e Oliveira (2010) analisaram amostras de carne de frango logo após a embalagem no frigorífico, após 7 dias a $4{ }^{\circ} \mathrm{C}$ e após 28 dias a $-20{ }^{\circ} \mathrm{C}$. Houve diferença significativa das contagens em UFC/g de Campylobacter spp. entre as amostras frescas e as armazenadas sob refrigeração ou congelamento, porém os autores não encontraram diferença significativa na incidência de $C$. jejuni nas amostras frescas e nas conservadas a baixas temperaturas, indicando que este microrganismo é capaz de sobreviver nas condições de armazenamento. As amostras analisadas no presente trabalho foram adquiridas no comércio resfriadas e os resultados encontrados também alertam que a refrigeração não garante a segurança deste produto com respeito a este micro-organismo.

Tentativas no sentido de diminuir a presença de Campylobacter na carne de frango têm apresentado resultados limitados porque os procedimentos de biosseguridade utilizados para o controle de Campylobacter nas granjas são deficientes e 
difíceis de serem mantidos. Apesar da Legislação Brasileira, estar cada vez mais exigente em relação ao controle higiênico-sanitário e de biosseguridade dos lotes avícolas nas granjas (BRASIL, 2013), a Legislação em vigor não estabelece padrões para Campylobacter em alimentos (BRASIL, 2001). Um estudo feito em um frigorífico de aves no Japão avaliou a contaminação entre diferentes lotes de frango durante a depenagem e evisceração. Campylobacter foi isolado em todas as aves abatidas após o processamento de um lote contaminado, o que sugere a sua fácil disseminação entre lotes (MIWA et al., 2003).

A contaminação cruzada devido à manipulação inadequada de alimentos no ambiente doméstico é considerada uma fonte importante de infecção (MATTICK et al., 2003). A necessidade de alertar o consumidor sobre como manipular e preparar adequadamente a carne de frango levou a Agência Nacional de Vigilância Sanitária a editar a Resolução RDC n 13 de janeiro de 2001. Essa Resolução é um Regulamento Técnico com instruções de uso, preparo e conservação de carne de aves e seus miúdos crus, resfriados e congelados, que devem constar nos rótulos desses produtos.

Embora o Brasil seja um grande exportador de carne de frango, existe pouca informação sobre a contaminação deste produto por Campylobacter spp. Estudos que avaliem melhor a ocorrência dessa bactéria, principalmente na cadeia produtiva dos produtos e subprodutos de aves, como o presente trabalho, são essenciais para auxiliar a tornar mais eficiente as medidas de controle e prevenção da doença.

É importante salientar que, por mais que esforços sejam feitos, a prevenção da contaminação durante o abate muitas vezes é impossível. O consumidor, portanto, precisa seguir as orientações contidas no rótulo quanto ao manuseio e preparo da carne de frango. Seguir essas orientações é considerado um ponto crítico de controle, que pode ajudar a prevenir a infecção humana por Campylobacter spp.

\section{Agradecimentos}

À CAPES, CNPq e Fundação Araucária pelo apoio financeiro concedido.

\section{Referências}

ABOLMAATY, A.; VU, C.; OLIVER, J.; LEVIN, R. E. Development of a new lysis solution for releasing genomic DNA from bacterial cells for DNA amplification by polymerase chain reaction. Microbios, Cambridge, v. 101, n. 400, p. 181-189, 2000.

ALTER. T.; GAULL, F.; FROEB, A.; FEHLHABER, K. Distribution of Campylobacter jejuni strains at different stages of a turkey slaughter line. Food Microbiology, London, v. 22, n. 4, p. 345-351, ago. 2005.

AQUINO, M. H. C.; PACHECO, A. P. G.; FERREIRA, M. C. S.; TIBANA, A. Frequency of isolation and identification of thermophilic campylobacters from animals in Brazil. The Veterinary Journal, London, v. 164, n. 2, p. 159-161, set. 2002.

AZEREDO, L. I.; LUCHESE, R. H.; LAURIAFILGUEIRAS, A. L. Campylobacter spp. em carne de ave crua: avaliação da etapa de resfriamento. Revista do Instituto Adolfo Lutz, São Paulo, v. 4, n. 69, p. 518-524. 2010.

BLASER, M. J. Epidemiologic and clinical features of Campylobacter jejuni infections. The Journal of Infectious Diseases, Cary, v. 176, n. 2, p. S103-S105, dez. 1997.

BRASIL. Agência Nacional de Vigilância Sanitária. Resolução RDC $\mathrm{n}^{\mathrm{o}}$ 12, de 02 de janeiro de 2001. Regulamento Técnico sobre padrões microbiológicos para alimentos. Anvisa - Agência Nacional de Vigilância Sanitária. Diário Oficial [da] União. Poder Executivo, 2001.Seção I, p. 45-53.

Ministério da Agricultura, Pecuária e

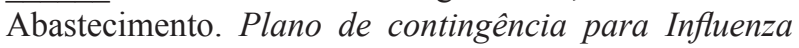
aviária e doença de Newcastle, versão 1.4. Brasília: Ministério da Agricultura, Pecuária e Abastecimento, 2013. Disponível em: <http://www3.servicos.ms.gov. br/iagro_ged/pdf/1906_GED.pdf $>$. Acesso em: 30 maio 2013.

CASARIL, K. B. P. B. Padronização de PCR tradicional e em tempo real para detecção de Campylobacter jejuni e Campylobacter coli em alimentos. 2010. Tese (Doutorado em Ciência de Alimentos) - Curso de PósGraduação em Ciência de Alimentos. Universidade Estadual de Londrina, Londrina. 
CENTERS FOR DISEASE CONTROL AND PREVENTION - CDC. Campylobacter general information. 2009. Disponível em: <http://www.cdc. gov/nczved/dfbmd/disease_listing/campylobacter gi.html\#2>. Acesso em: 12 jul. 2009.

COSTA, C. A. R. Avaliação da exposição do consumidor à Listeria monocytogenes Salmonella spp., Campylobacter spp. e Escherichia coli produtora de toxina Shiga em produtos cárneos refrigerados comercializados no município de São Paulo. 2010. Tese (Doutorado em Ciência de Alimentos) - Curso de Pós-Graduação em Ciência de Alimentos. Universidade de São Paulo, São Paulo.

COX, N. A.; RICHARDSON, L. J.; MAURER, J. J.; BERRANG, M. E.; FEDORKA-CRAY, P. J.; BUHR, R. J.; BYRD, J. A.; LEE, M. D.; HOFACRE, C. L.; O'KANE, P. M.; LAMMERDING, A. M.; CLARK, A. G.; THAYER, S. G.; DOYLE, M. P. Evidence for horizontal and vertical transmission in Campylobacter passage from hen to her progeny. Journal of Food Protection, Des Moines, v. 75, n. 10, p. 1896-1902, out. 2012.

DIAS, T. C.; QUEIROZ, D. M. M.; MENDES, E. N.; PERES, J. N. Chicken carcasses as a source of Campylobacter jejuni in Belo Horizonte, Brazil. Revista do Instituto de Medicina Tropical de São Paulo, São Paulo, v. 32, n. 6, p. 414-418, nov./dec. 1990.

DOCHERTY, L.; ADAMS, M. R.; PATEL, P.; MCFADDEN, J. The magnetic immuno-polymerase chain reaction assay for the detection of Campylobacter in milk and poultry. Letters in Applied Microbiology, Oxford, v. 22, n. 4, p. 288-292, abr. 1996.

EUROPEAN FOOD SAFETY AUTHORITY - EFSA. Analysis of the baseline survey on the prevalence of Campylobacter in broiler batches of Campylobacter and Salmonella on broiler carcasses in the EU, 2008 - part A. Campylobacter and Salmonella prevalence estimates. 2008. Disponível em: <http://www.efsa.europa.eu/en/ efsajournal/pub/1503.htm>. Acesso em: 20 set. 2012.

FORSYTHE, S. J. Microbiologia da segurança alimentar. São Paulo: Editora Artmed, 2002. 424 p.

FRANCHIN, P. R.; OGLIARI, P. J.; BATISTA, C. R. V. Frequency of thermophilic Campylobacter in broiler chickens during industrial processing in a Southern Brazil slaughterhouse. British Poultry Science, Edinburgh, v. 48, n. 2, p. 127-132, abr. 2007.

HOORFAR, J.; AHRENS, P.; RÅDSTRÖM, P. Automated 5' nuclease PCR assay for identification of Salmonella enterica. Journal of Clinical Microbiology, Washington D.C., v. 38, n. 9, p. 3429-3435, set. 2000.
HUMPHREY, T.; O'BRIEN, S.; MADSEN, M. Campylobacters as zoonotic pathogens: a food production perspective. International Journal of Food Microbiology, Washington D.C. v. 117, n. 3, p. 237-257, jul. 2007.

JOFRÉ, A.; MARTIN, B.; GARRIGA, M.; HUGAS, M.; PLA, M.; RODRÍGUEZ-LÁZARO, D.; AYMERICH, T. Simultaneous detection of Listeria monocytogenes and Salmonella by multiplex PCR in cooked ham. Food Microbiology, London, v. 22, n. 1, p. 109-115, jan. 2005.

LINTON, D.; OWEN, R. J.; STANLEY, J. Rapid identification by PCR of the genus Campylobacter and of five Campylobacter species enteropathogenic for man and animals. Research in Microbiology, Paris, v. 147, n. 9, p. 707-718, nov./dez. 1996.

LOPES, G. V. Campylobacter spp. no abate e varejo: ocorrência em carcaças de bovinos para exportação e em cortes refrigerados de aves e bovinos. 2009. Dissertação (Mestrado em Ciência de Alimentos) - Curso de PósGraduação em Ciência de Alimentos. Universidade de São Paulo, São Paulo.

LÜBECK, P. S.; WOLFFS, P.; ON, S. L. W.; AHRENS, P.; RADSTRÖM, P.; HOORFAR, J. Toward an international standard for PCR-based detection of foodborne thermotolerant campylobacters: assay development and analytical validation. Applied and Enviromental Microbiology, Washington D.C., v. 69, n. 9, p. 56645669, set. 2003.

MAZIERO, M. T. ; OLIVEIRA, T. C. R. M. Efect of refrigeration and frozen storage on the Campylobacter jejuni recovery from naturally contaminated broiler carcasses. Brazilian Journal of Microbiology, São Paulo, v. 41, n. 2, p. 501-505, abr./jun. 2010.

MEAD, G. Campylobacter update - the challenge. International Poultry Production, East Yorkshire, v. 12, n. 4, p. 26-29. 2004.

MATTICK, K.; DURHMAN, K.; DOMINIGUE, G.; JØRGENSEN, F.; SEN, M.; SCHAFFNER, D. W.; HUMPHREY, T. The survival of foodborne pathogens during domestic washing up and subsequent transfer onto washing-up sponges, kitchen surfaces, and food. International Journal of Food Microbiology, Torino, v. 85, n. 3, p. 213-226, ago, 2003.

MIWA, N.; TAKEGAHARA, Y.; TERAI, K; KATO, H.; TAKEUCHI, T. Campylobacter jejuni contamination on broiler carcasses of $C$. jejuni-negative flocks during processing in a Japanese slaughterhouse. International Journal of Food Microbiology, Torino, v. 84, n. 1, p. 105109, jul. 2003.

NATIONAL ANTIMICROBIAL RESISTANCE MONITORING SYSTEM - NARMS retail meat report, 
2010. Department of Health and Human Services, FDA, USA. Disponível em: <http://www.fda.gov/downloads/ AnimalVeterinary/SafetyHealth/AntimicrobialResistance/ NationalAntimicrobialResistanceMonitoringSystem/ UCM293581.pdf>. Acesso em: 25 set. 2012.

NEWELL, D. G.; FEARNLEY, C. Sources of Campylobacter colonization in broiler chickens. Applied and Environmental Microbiology, Washington D.C., v. 69, n. 8, p. 4343-4351, ago. 2003.

OLSEN, K. N.; LUND, M.; SKOV, J.; CHRISTENSEN, L. S.; HOORFAR, J. Detection of Campylobacter bacteria in air samples for continuous real-time monitoring of Campylobacter colonization in broiler flocks. Applied and Enviromental Microbiology, Washington D.C., v. 75, n. 7, p. 2074-2078, abr. 2009.

PARK, S. F. The physiology of Campylobacter species and its relevance to their role as foodborne pathogens. International Journal of Food Microbiology, Torino, v. 74, n. 3, p. 177-188, abr. 2002.

SIMMONS, M.; HIETT, K. L.; STERN, N. J.; FRANK, J. F.. Comparison of poultry exudate and carcass rinse sampling methods for the recovery of Campylobacter spp. subtypes demonstrates unique subtypes recovered from exudate. Journal of Microbiological Methods, Amsterdam, v. 74, n. 2-3, p. 89-93, ago. 2008.

UNIÃO BRASILEIRA DE AVICULTURA - UBA. Relatório Anual 2011 da União Brasileira de Avicultura.
2013. Disponível em: <http://www.abef.com.br/ubabef/ exibenoticiaubabef.php?notcodigo $=2761>$. Acesso em: 23 nov. 2012.

UYTTENDAELE, M.; SCHUKKINK', R.; GEMEN', B. V.; DEBEVERE, J. ldentification of Campylobacter jejuni, Campylobacter coli and Campylobacter lari by the nucleic acid amplification system NASBAR. Journal of Applied Bacteriology, London, v. 77, n. 6, p. 694-701. 1994.

VANCAMP, G.; FIERENS, H.; VANDAMME, P.; GOOSENS, H.; HUYGHEBAERT, A.; WACHTER, R. D. Identification of enteropathogenic Campylobacter species by oligonucleotide probes and polymerase chain reaction based on 16s rRNA genes. Systemic and Applied Microbiology, Maryland Heights, v. 16, n. 1, p. 30-36, abr. 1993.

YAN, S. S.; PENDRAK, M. L.; FOLEY, S. L.; POWERS, J. H. Campylobacter infection and Guillain-Barré syndrome: public health concerns from a microbial food safety perspective. Clinical and Applied Immunology Reviews, Maryland Heights, v. 5, p. 285-305, set./out. 2005.

WORLD HEALTH ORGANIZATION - WHO. FAO/ WHO Expert meeeting on Salmonella and Campylobacter in chicken meat, 4-8. may 2009. Disponível em: $<$ http:// www.who.int/foodsafety/micro/jemra/meetings/may09/ en/index.html>. Acesso em: 20 jul. 2012. 
